\title{
Diagnostic ability of OCT parameters and retinal ganglion cells count in identification of glaucoma in myopic preperimetric eyes
}

\author{
Teresa Rolle* $\mathbb{D}^{*}$, Beatrice Bonetti, Alberto Mazzucco and Laura Dallorto
}

\begin{abstract}
Background: The aim of the study is to evaluate the diagnostic ability of OCT parameters and retinal ganglion cells (RGCs) count in identify glaucomatous disease in myopic preperimetric eyes.

Methods: This was a cross-sectional observational study. The study group consisted of 154 eyes: 36 controls, 64 preperimetric (PPG), and 54 primary openangle glaucoma (POAG) eyes. Each group was divided into three subgroups based on axial length: emmetropic, myopic with axial length (AL) $<25 \mathrm{~mm}$, and myopic with $\mathrm{AL}>25 \mathrm{~mm}$, to analyze the effect of myopia. The RGCs count was obtained using a model described later. As regard the influence of myopia on OCT parameters and RGC count, we performed Pearson's correlation. The Area Under Receiver Operator Characteristics Curves (AUROC curves) evaluated which parameter had the best sensitivity and specificity in identifying glaucoma in myopic eyes.
\end{abstract}

Results: In Pearson's test, all Ganglion Cell Complex (GCC) thicknesses showed the weakest and less significant correlation with AL in all groups. All the AUROCs were statistically significant, and above 0.5. Inferior GCC and Global Loss Volume (GLV) showed the highest AUCs in all myopic group and the best diagnostic ability in distinguishing control from glaucomatous eyes. RGCcount showed good AUROC in all groups, with sensitivities of about 83\% in myopic eyes, and specificity over $91 \%$ in all groups.

Conclusions: GCC is the parameter less influenced by the AL, and the inferior GCC and the GLV have the best diagnostic performance. The RGCcount has good sensitivity and specificity, so it can be used as a complementary test in the diagnosis of glaucoma in myopic preperimetric eyes.

Keywords: Ganglion cells, Glaucoma, Myopia, Optical coherence tomography

\section{Background}

Myopia and glaucoma are two of the commonest causes of impaired vision in the world population. The number of people affected by myopia is estimated to be 5 billion by 2050 [1]; more than 100 million people currently suffer from blindness and irreversible visual impairment due to glaucoma [2,3]. Myopic eyes have a higher risk of glaucoma [4]. The link between the two diseases

\footnotetext{
* Correspondence: teresa.rolle@unito.it

Eye Clinic, Department of Surgical Sciences, University of Torino, Via Cherasco 23, Torino, Italy
}

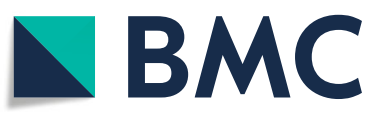

(c) The Author(s). 2020 Open Access This article is licensed under a Creative Commons Attribution 4.0 International License, which permits use, sharing, adaptation, distribution and reproduction in any medium or format, as long as you give appropriate credit to the original author(s) and the source, provide a link to the Creative Commons licence, and indicate if changes were made. The images or other third party material in this article are included in the article's Creative Commons licence, unless indicated otherwise in a credit line to the material. If material is not included in the article's Creative Commons licence and your intended use is not permitted by statutory regulation or exceeds the permitted use, you will need to obtain permission directly from the copyright holder. To view a copy of this licence, visit http://creativecommons.org/licenses/by/4.0/. The Creative Commons Public Domain Dedication waiver (http://creativecommons.org/publicdomain/zero/1.0/) applies to the data made available in this article, unless otherwise stated in a credit line to the data.

seems to be the more easily deformable lamina cribrosa in myopic eyes. Myopic changes consist in longer axial lengths and greater vitreous chamber depths together with alterations in connective tissue which may increase susceptibility of optic disc to glaucomatous damage [5].

With the ophthalmoscopic evaluation alone, it can be difficult to distinguish glaucomatous damage from myopia for a number of reasons [6]. In myopia the use of structural or functional tests for the diagnosis of glaucoma is not fully reliable, for the presence of peculiar alterations such as posterior staphylomas or macular 
atrophy. Thus, it is absolutely necessary to pay close attention to distinguish the alterations of glaucoma from those of myopia to avoid overdiagnosis of glaucoma in myopic eyes [7]. Recently, empirical formulas derived from the combination of structural and functional measures to estimate the number of RGCs have been developed [8-11], and several studies state they are more accurate than the individual parameters they derive from for assessing the severity and progression of glaucoma [9-13].

\section{Methods}

This cross-sectional observational study took place at the Glaucoma Center of the Eye Clinic, Department of Surgical Sciences, University of Turin, Italy. The methods conformed to the principles of the Declaration of Helsinki; we obtained the informed consent of all subjects and the approval of the Ethics Committee (University and Polyclinic San Giovanni Battista of Turin).

The inclusion criteria for admission of study subjects were: $18 \leq$ age $\leq 80$ years, best-corrected visual acuity $(B C V A) \geq 20 / 30$, spherical equivalent between $+1.00 \mathrm{D}$ and $-1.00 \mathrm{D}$ for emmetropic subjects, and between 3.00D and $-7.00 \mathrm{D}$ for myopic subjects, and gonioscopic evidence of open angle. No subjects with previous ocular surgery, or with ocular, systemic or neurological pathologies causing perimetric defects were included. Patients with macular pathologic changes related to myopia were excluded from the study, as myopia is frequently associated with macular changes and degenerations that may affect ganglion cell count.

We performed a full eye examination, FourierDomain-OCT (FD-OCT RTVue-100 software version A4, 5, 0, 59; Optovue, Fremont, CA, USA) for peripapillary and macular imaging, and measurement of axial lenght with low-coherence interferometry system (Aladdin biometer, Topcon). Standard Automated Perimery was performed with program 24-2 of the Humphrey Field Analyzer (HFA; Carl Zeiss Meditec, Jena, Germany), using Swedish Interactive Threshold Algorithm (SITA) Standard strategy, with reliability criteria of fixation losses $\leq 20 \%$, false positives and false negatives $\leq 33 \%$. The study included three groups of subjects: preperimetric glaucomatous subjects (PPG), primary open-angle glaucoma (POAG) subjects, and a healthy group that was required to have negative family history of glaucoma and normal IOP $(\leq 21 \mathrm{mmHg})$, visual field (VF) test and optic nerve head $(\mathrm{ONH})$ appearance. PPG subjects had IOP $>21$ $\mathrm{mmHg}$, and changes in optic nerve (cup-disc ratio alteration/disc hemorrhages/rim notching/diffused or localized RNFL defects), but no defects on VF. POAG subjects had IOP $>21 \mathrm{mmHg}$, and glaucomatous alterations in optic disc and VF, as stated by Hodapp-Parrish-Anderson criteria for diagnosing glaucomatous damage [14]. For the evaluation of optic nerve head appearance, we used slitlamp biomicroscopy of posterior segment with a 78-D lens. Each group was further divided into three subgroups based on axial length: emmetropic, myopic with $\mathrm{AL}<25$ $\mathrm{mm}$ and myopic with $\mathrm{AL}>25 \mathrm{~mm}$, in order to analyze the effect of mild and moderate myopia.

\section{FD-OCT RTVue-100}

We used the Glaucoma Protocol of FD-OCT RTVue100 to acquire RNFL thickness measurements. We detailed this protocol in a previous study (Rolle et al.) [15]

\section{Estimate of retinal and macular ganglion cell count}

To estimate RGC number we used the model by Medeiros et al. $[9-11,16]$ based on the empirical formulas of Harwerth et al. [8].

We described this formula in detail in our previous article (Rolle et al.) [15].

\section{Statistical analysis}

We used Microsoft Excel 2016 worksheets and the SPSS statistical program for Windows (version 19.0, SPSS Inc., Chicago, IL) for the collection, processing and statistical analysis of the results. The analysis of variance (ANOVA) and $x^{2}$ test was used to assess the comparability of the groups for continuous and dichotomic variables respectively.

For each of the three groups (controls, PPG and POAG) the Pearson's linear correlation coefficient was calculated to evaluate how the measured parameters are influenced by the AL increasing. Then, each group was further subdivided into 3 subgroups (emmetropes, myopic eyes with $\mathrm{AL}<25 \mathrm{~mm}$ and myopic eyes with $\mathrm{AL}>$ $25 \mathrm{~mm}$ ) to analyze the effects of mild and moderate axial myopia by the Mann-Whitney U test (Fig. 1).

To investigate the ability of OCT parameters and RGCcount to diagnose glaucoma, we calculated areas under the receiver operating characteristic (AUROC). We compare the AUROCs between RGCcount and OCT parameters in all subgroups with different axial length (emmetropes, all myopic eyes, and myopes with $\mathrm{AL}<25 \mathrm{~mm}$ and $>25 \mathrm{~mm}$ ) using the method described by DeLong et al. [17]. For the calculation of AUROC and for all the comparisons between AUROCs we used a statistical software package (MedCalc v. 12.0; MedCalc Statistical software, Marakierke, Belgium).

For all statistical analysis, a $p$ value $<0.05$ was considered statistically significant.

\section{Results}

The study group consisted of 154 eyes: 36 controls, 64 PPG, and 54 POAG eyes. Demographic characteristics of the study population are illustrated in Tables 1 and 2 . 


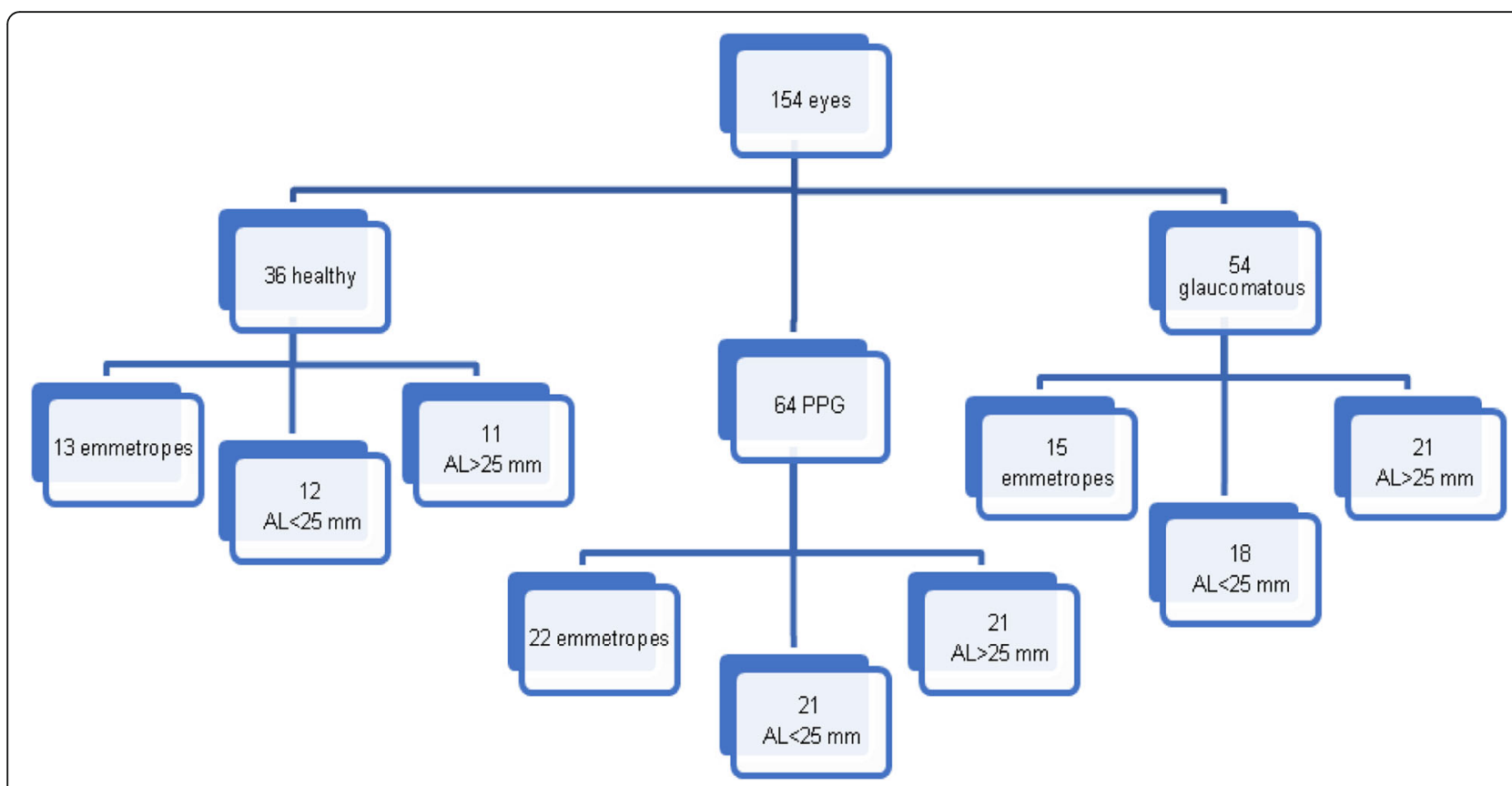

Fig. 1 Graphical representation of the subdivision of the study sample into subgroups

In Table 1 the ANOVA and $x^{2}$ test showed that the groups are comparable for age, sex, and refraction. Ttest between groups shows that groups are comparable also for AL.

Glaucomatous eyes have significantly worse VF MD and PSD than control and PPG eyes $(P<0.001)$.

RNFLavg and RGC number reduce with the progression of glaucomatous damage, as demonstrated in previous studies $[15,18]$.
As regard the influence of myopia on OCT parameters and RGC count, we performed the Pearson's correlation of axial length with RGC (Table 3). RNFL shows a significant negative moderate correlation with $\mathrm{AL}$ in all groups, while GCC has a weak positive correlation with $\mathrm{AL}$ not significant in control group, a weak negative correlation in PPG and POAG, statistically significant except for GCCavg and GCCsup in POAG group. FLV seems to be strongly correlated with AL (moderate

Table 1 Comparison of the Demographic and Clinical Characteristics of Control,PPG, and POAG Eyes

\begin{tabular}{|c|c|c|c|c|c|c|c|}
\hline \multirow[t]{2}{*}{ Parameters } & \multirow[t]{2}{*}{ Control } & \multirow[t]{2}{*}{ PPG } & \multirow[t]{2}{*}{ POAG } & \multirow[t]{2}{*}{$P$-value } & \multicolumn{3}{|c|}{$P$-value for $\mathrm{t}$ test between groups } \\
\hline & & & & & $\begin{array}{l}\text { Control vs } \\
P P G\end{array}$ & $\begin{array}{l}\text { Control vs } \\
\text { POAG }\end{array}$ & $\begin{array}{l}\text { PPG VS } \\
P O A G\end{array}$ \\
\hline Eyes (n) & 36 & 64 & 54 & & & & \\
\hline Age (y) & $55.51(7.72)$ & $56.00(7.28)$ & $59.93(7.28)$ & $0.15^{*}$ & $0.82 \neq$ & $0.06 \neq$ & $0.18 \neq$ \\
\hline $\operatorname{Sex}(M / F)$ & $16 / 20$ & $15 / 39$ & $22 / 32$ & $0.21 t$ & $0.102 \neq$ & $0.73 \neq$ & $0.16 \neq$ \\
\hline Refraction (D) & $-2.53(2.45)$ & $-2.49(2.65)$ & $-3.24(2.74)$ & $0.29 *$ & $0.93 \neq$ & $0.21 \neq$ & $0.13 \neq$ \\
\hline Axial lenght (mm) & $24.18(1.16)$ & $24.28(2.19)$ & $24.99(2.75)$ & $0.03^{*}$ & $0.78 \neq$ & $0.04 \neq$ & $0.03 \neq$ \\
\hline $\mathrm{MD}(\mathrm{dB})$ & $-0.48(0.83)$ & $-0.59(1.64)$ & $-6.50(6.74)$ & $<.001^{*}$ & $0.73 \neq$ & $<.001 \neq$ & $<.001 \neq$ \\
\hline PSD (dB) & $1.63(0.37)$ & $1.75(0.96)$ & $6.30(3.63)$ & $<.001^{*}$ & $0.42 \neq$ & $<.001 \neq$ & $<.001 \neq$ \\
\hline RNFLavg $(\mu)$ & $108.22(10.90)$ & $93.70(9.95)$ & $80.24(13.2)$ & $<.001^{*}$ & $<.001 \neq$ & $<.001 \neq$ & $<.001 \neq$ \\
\hline GCCavg $(\mu)$ & $97.11(6.46)$ & $85.52(7.32)$ & 75.19 (10.95) & $<.001^{*}$ & $<.001 \neq$ & $<.001 \neq$ & $<.001 \neq$ \\
\hline $\begin{array}{l}\text { Estimated total RGC } \\
\text { count }(n)\end{array}$ & $1,140,520.81(138,535.47)$ & $958,579.68(150,472.40)$ & $616,463.06(226,325.70)$ & $<.001^{*}$ & $<.001 \neq$ & $<.001 \neq$ & $<.001 \neq$ \\
\hline
\end{tabular}

The parameters are expressed as mean and SD; MD Mean deviation of SAP, PSD Pattern standard deviation of SAP. RNFL Retinal Nerve Fiber Layer, GCC Ganglion Cell Complex, RGC Retinal Ganglion Cell

*P-value for ANOVA, significant for $p<0.05$

$+P$-value for $x 2$ test, significant for $p<0.05$

$\ddagger P$-value for $t$ test between groups, significant for $p<\alpha$ adjusted with Bonferroni correction ( $p$-value with IC $95 \% /$ number of comparisons $=0.05 / 3=0.0167$ ) 
Table 2 Comparison of the Demographic and Clinical Characteristics of Emmetropic.Eyes. Myopes with $\mathrm{AL}<25 \mathrm{~mm}$ and Myopes with $\mathrm{AL}>25 \mathrm{~mm}$

\begin{tabular}{|c|c|c|c|c|c|c|c|}
\hline \multirow[t]{2}{*}{ Parameters } & \multirow[t]{2}{*}{ Emmetropes } & \multirow{2}{*}{$\begin{array}{l}\text { Myopes } \\
\mathrm{AL}<25 \mathrm{~mm}\end{array}$} & \multirow{2}{*}{$\begin{array}{l}\text { Myopes } \\
\mathrm{AL}>25 \mathrm{~mm}\end{array}$} & \multirow[t]{2}{*}{$P$-value } & \multicolumn{3}{|c|}{$P$-value for $\mathrm{t}$ test between groups } \\
\hline & & & & & $\begin{array}{l}\text { Emmetropes vs } \\
\text { Myopes } \\
\mathrm{AL}>25 \mathrm{~mm}\end{array}$ & $\begin{array}{l}\text { Emmetropes vs } \\
\text { Myopes } \\
\mathrm{AL}<25 \mathrm{~mm}\end{array}$ & $\begin{array}{l}\text { Myopes } \mathrm{AL}>25 \mathrm{~mm} \\
\text { vs } \\
\text { Myopes } \mathrm{AL}<25 \mathrm{~mm}\end{array}$ \\
\hline Eyes $(n)$ & 50 & 51 & 53 & & & & \\
\hline Age (y) & $58.92(8.67)$ & $57.94(10.76)$ & $57.89(11.36)$ & $0.85^{*}$ & $0.62 \neq$ & $0.61 \neq$ & $0.98 \neq$ \\
\hline $\operatorname{Sex}(M / F)$ & $18 / 32$ & $16 / 35$ & $19 / 34$ & $0.85 t$ & $0.62 \neq$ & $0.84 \neq$ & $0.63 \neq$ \\
\hline Refraction (D) & $0.64(0.34)$ & $-3.62(0.43)$ & $-5.24(1.10)$ & $<.001^{*}$ & $<.001 \neq$ & $<.001 \neq$ & $<.001 \neq$ \\
\hline Axial lenght (mm) & $22.82(0.80)$ & $24.41(0.61)$ & $26.23(1.30)$ & $<.001^{*}$ & $<.001 \neq$ & $<.001 \neq$ & $<.001 \neq$ \\
\hline $\mathrm{MD}(\mathrm{dB})$ & $-2.16(4.43)$ & $-2.18(5.37)$ & $-3.50(5.30)$ & $0.24^{*}$ & $0.96 \neq$ & $0.14 \neq$ & $0.16 \neq$ \\
\hline PSD (dB) & $2.77(2.23)$ & $3.39(3.42)$ & $3.76(3.67)$ & $0.27^{*}$ & $0.30 \neq$ & $0.09 \neq$ & $0.55 \neq$ \\
\hline RNFLavg $(\mu)$ & $96.43(14.06)$ & $95.23(16.66)$ & $86.02(13.58)$ & $0.002^{*}$ & $0.58 \neq$ & $0.0005 \neq$ & $0.008 \neq$ \\
\hline GCCavg $(\mu)$ & $87.63(7.70)$ & $85.12(14.50)$ & $81.59(11.87)$ & $0.04^{*}$ & $0.22 \neq$ & $0.003 \neq$ & $0.23 \neq$ \\
\hline $\begin{array}{l}\text { Estimated total RGC } \\
\text { count }(n)\end{array}$ & $\begin{array}{l}941,639.43 \\
(259,924.16)\end{array}$ & $\begin{array}{l}918,347.12 \\
(279,783.75)\end{array}$ & $\begin{array}{l}786,566.29 \\
(260,723.37)\end{array}$ & $0.007^{*}$ & $0.57 \neq$ & $0.002 \neq$ & $0.02 \neq$ \\
\hline
\end{tabular}

The parameters are expressed as mean and SD; MD Mean deviation of SAP, PSD Pattern standard deviation of SAP. RNFL Retinal Nerve Fiber Layer, GCC Ganglion Cell Complex, RGC Retinal Ganglion Cell

*P-values for ANOVA, significant for $p<0.05$

$+P$-values for $X^{2}$ test, significant for $p<0.05$

$\ddagger P$-value for $t$ test between groups, significant for $p<a$ adjusted with Bonferroni correction ( $p$-value with IC $95 \% /$ number of comparisons $=0.05 / 3=0.0167$ )

significant positive correlation with AL in all groups), GLV has a significant positive moderate correlation with AL only in PPG group, while in control group the correlation is weak and not significant. Also RGCcount seems to be correlated with AL, because it has a moderate significant correlation in all groups.

To better evaluate the influence of myopia, we subdivided each group in three subgroups, basing on refractive error emmetropic eyes with defect between $+1.00 \mathrm{sf}$

Table 3 Pearson's correlation between OCT parameters and RGC count and axial lenght

\begin{tabular}{|c|c|c|c|}
\hline \multirow[t]{2}{*}{ Parameters } & Control & PPG & POAG \\
\hline & $R(p)$ & $R(p)$ & $R(p)$ \\
\hline $\mathrm{MD}(\mathrm{dB})$ & $-0.28(\mathbf{0 . 0 5})$ & $-0.07(0.56)$ & $-0.34(\mathbf{0 . 0 1 )}$ \\
\hline RNFLavg $(\mu \mathrm{m})$ & $-0.46(\mathbf{0 . 0 0 2})$ & $-0.33(\mathbf{0 . 0 0 3 )}$ & $-0.3(\mathbf{0 . 0 1 )}$ \\
\hline RNFLsup ( $\mu \mathrm{m})$ & $-0.31(\mathbf{0 . 0 3 )}$ & $-0.28(\mathbf{0 . 0 1 )}$ & $-0.3(\mathbf{0 . 0 3 )}$ \\
\hline RNFLinf $(\mu \mathrm{m})$ & $-0.55(<.001)$ & $-0.31(\mathbf{0 . 0 0 7 )}$ & $-0.3(\mathbf{0 . 0 1 )}$ \\
\hline GCCavg $(\mu \mathrm{m})$ & $0.07(0.3)$ & $-0.29(\mathbf{0 . 0 1 )}$ & $-0.15(0.1)$ \\
\hline GCCsup $(\mu \mathrm{m})$ & $0.1(0.3)$ & $-0.23(\mathbf{0 . 0 3 )}$ & $-0.04(0.4)$ \\
\hline GCCinf $(\mu \mathrm{m})$ & $0.045(0.4)$ & $-0.31(\mathbf{0 . 0 0 6})$ & $-0.24(\mathbf{0 . 0 4 )}$ \\
\hline FLV \% & $0.44(\mathbf{0 . 0 0 4 )}$ & $0.43(<.001)$ & $0.57(<.001)$ \\
\hline GLV \% & $0.22(0.1)$ & $0.48(<.001)$ & $0.26(\mathbf{0 . 0 3})$ \\
\hline RGCcount (n) & $-0.58(<.001)$ & $-0.3(<.001)$ & $-0.32(\mathbf{0 . 0 0 7 )}$ \\
\hline
\end{tabular}

$P$-values significant for $p<0.05$ and $-1.00 \mathrm{sf}$, and myopic eyes with defect between $3.00 \mathrm{sf}$ and $-7.00 \mathrm{sf}$, and in these latter eyes axial length superior or inferior to $25 \mathrm{~mm}$. This cut-off was chosen because it is two standard deviations from the reference average of the main normative databases [19].

In Tables 4, 5, 6 we resumed the results of MannWhitney U Test between PPG and control subgroups. In comparisons between control subgroups with different axial length (Table 6) we can merely evaluate the influence of myopia on OCT parameters. In all comparisons the MD is not statistically significant, a sign that there is no influence of any myopic damage on the functional aspect. In all the subgroups we can observe a difference between emmetropes and myopes for both macular and papillary OCT parameters, a sign of an influence of myopia on the structural aspect.

In Table 7 we compared emmetropic PPG eyes and all myopic PPG eyes with no distinguishing about axial length, and the difference is statistically significant for all parameters.

The AUCs of MD, OCT parameters and RGCcount of emmetropes, myopes with $\mathrm{AL}<25 \mathrm{~mm}$, myopes with $\mathrm{AL}>25 \mathrm{~mm}$ and all myopes subjects are summarized in Table 8 and Fig. 2; All the AUROCs are statistically significant, and above 0.5. Inferior GCC and Global Loss Volume (GLV) show the highest AUCs in all myopic groups and the best diagnostic ability in distinguishing control from glaucomatous eyes. Both GCCinf and GLV 
Table 4 RNFL and GCC measurement and RGCcount in PPG subgroups

\begin{tabular}{|c|c|c|c|c|c|c|}
\hline Parameters & $\begin{array}{l}\text { PPG emmetropic } \\
(N=22)\end{array}$ & $\begin{array}{l}\text { PPG with AL } \\
<25 \mathrm{~mm}(\mathrm{~N}=21)\end{array}$ & $\begin{array}{l}\text { PPG with AL } \\
>25 \mathrm{~mm}(\mathrm{~N}=21)\end{array}$ & $\begin{array}{l}\text { PPG emmetropic vs } \\
\text { PPG with } \mathrm{AL}<25 \mathrm{~mm}\end{array}$ & $\begin{array}{l}\text { PPG emmetropic } \\
\text { vs PPG with AL } \\
>25 \mathrm{~mm}\end{array}$ & $\begin{array}{l}\text { PPG with AL } \\
<25 \mathrm{~mm} \text { vs } \\
\text { PPG with AL } \\
>25 \mathrm{~mm}\end{array}$ \\
\hline & & & & \multicolumn{3}{|c|}{$P$-values } \\
\hline $\mathrm{MD}(\mathrm{dB})$ & $-0.98(1.52)$ & $0.18(1.26)$ & $-0.94(1.89)$ & 0.12 & 0.6 & 0.07 \\
\hline RNFL avg. $(\mu \mathrm{m})$ & $97.17(10.82)$ & $95.0(8.05)$ & $88.68(9.07)$ & 0.4 & 0.009 & 0.02 \\
\hline RNFL sup $(\mu \mathrm{m})$ & $98.01(11.01)$ & $93.52(8.78)$ & $90.30(12.07)$ & 0.11 & 0.02 & 0.21 \\
\hline RNFL inf $(\mu m)$ & $96.31(11.84)$ & $96.66(10.66)$ & $87.06(11.22)$ & 0.96 & 0.02 & 0.008 \\
\hline GCC avg. $(\mu m)$ & $88.20(6.68)$ & $86.73(4.60)$ & $81.52(8.64)$ & 0.28 & 0.005 & 0.005 \\
\hline GCC sup $(\mu \mathrm{m})$ & $88.99(7.31)$ & $87.86(5.11)$ & $82.82(8.16)$ & 0.29 & 0.005 & 0.007 \\
\hline GCC inf $(\mu m)$ & $87.40(7.04)$ & $85.66(5.02)$ & $80.22(9.91)$ & 0.3 & 0.01 & 0.03 \\
\hline FLV \% & $1.68(2.22)$ & $2.41(2.74)$ & $4.50(4.67)$ & 0.06 & 0.01 & 0.2 \\
\hline GLV \% & $9.59(5.71)$ & $12.29(4.68)$ & $18.07(7.16)$ & 0.08 & $<.001$ & 0.005 \\
\hline RGC count $(n)$ & $1,002,394.31 \quad(189,401.24)$ & $986,664.15(91,736.86)$ & $884,594.19(128,656.99)$ & 0.96 & 0.05 & 0.007 \\
\hline
\end{tabular}

The parameters are expressed as mean and SD. There is no difference between emmetropic and mild myopic PPG, while all the parameters analyzed are statistically significant in comparison between emmetropes and high myopic PPG, and between mild and high myopic PPG. $P$-values significant for $p<0.05$

have sensibility $>95 \%$ in all groups, except GLV sensitivity in all myopes' group (92.59\%).

RNFLavg and MD are used in the formula of RGCcount of Medeiros et al. [9] to calculate the RGC number. We compared the diagnostic performance of both parameters with that of RGCcount (see Table 8), using the method of De Long [17], to assess whether the retinal ganglion cell count adds more diagnostic information than the respective parameters from which it is derived. RGCcount performs significantly better than MD in all groups, and almost the same than RNFLavg with no statistical significant differences.

\section{Discussion}

Patients with high myopia has a sixfold increased odds to develop glaucomatous disease [20], and in this case the early diagnosis is mandatory and needs tests with high sensitivity and specificity [21].

The evaluation of peripapillary RNFL is used in common clinical practice to detect the presence of glaucomatous damage [22], but in high myopia its interpretation is made difficult by the frequent presence of optic nerve tilt. Shin et al. [23] showed that optic disc tilt reduce RNFL diagnostic ability in detecting glaucoma, while it doesn't influence ganglion cell-inner plexiform layer (GCIPL)

Table 5 RNFL and GCC measurement and RGCcount in PPG versus control eyes of comparable AL

\begin{tabular}{|c|c|c|c|c|c|c|c|c|c|}
\hline Parameters & $\begin{array}{l}\text { PPG } \\
\text { emmetropic } \\
(N=22)\end{array}$ & $\begin{array}{l}\text { PPG with AL } \\
<25 \mathrm{~mm} \\
(N=21)\end{array}$ & $\begin{array}{l}\text { PPG with } \\
\mathrm{AL}>25 \mathrm{~mm} \\
(\mathrm{~N}=21)\end{array}$ & $\begin{array}{l}\text { Emmetropic } \\
\text { Control } \\
(N=13)\end{array}$ & $\begin{array}{l}\text { Control with } \\
\mathrm{AL}<25 \mathrm{~mm} \\
(N=12)\end{array}$ & $\begin{array}{l}\text { Control with } \\
\mathrm{AL}>25 \mathrm{~mm} \\
(\mathrm{~N}=11)\end{array}$ & $\begin{array}{l}\text { PPG emmetropic } \\
\text { vs emmetropic } \\
\text { control }\end{array}$ & $\begin{array}{l}\text { PPG with } \mathrm{AL} \\
<25 \mathrm{~mm} \text { vs } \\
\text { control with } \\
\mathrm{AL}<25 \mathrm{~mm}\end{array}$ & $\begin{array}{l}\text { PPG with } \mathrm{AL} \\
>25 \mathrm{~mm} \text { vs } \\
\text { control with } \\
\mathrm{AL}>25 \mathrm{~mm}\end{array}$ \\
\hline & & & & & & & & \multicolumn{2}{|l|}{$P$-values } \\
\hline $\mathrm{MD}(\mathrm{dB})$ & $-0.98(1.52)$ & $-0.94(1.89)$ & $0.18(1.26)$ & $-0.12(0.85)$ & $-0.64(0.79)$ & $-0.73(0.76)$ & 0.06 & 0.05 & 0.92 \\
\hline RNFL avg. $(\mu \mathrm{m})$ & $97.17(10.82)$ & $88.68(9.07)$ & $95.09(8.05)$ & $109.76(9.79)$ & $114.54(10.61)$ & $100.15(7.59)$ & 0.006 & $<.001$ & 0.003 \\
\hline RNFL sup $(\mu \mathrm{m})$ & $98.01(11.01)$ & $90.30(12.07)$ & $93.52(8.78)$ & $106.45(9.32)$ & $113.45(13.76)$ & $101.04(10.04)$ & 0.06 & $<.001$ & 0.01 \\
\hline RNFL inf $(\mu \mathrm{m})$ & $96.31(11.84)$ & $87.06(11.22)$ & $96.66(10.66)$ & $113.08(11.48)$ & $115.62(9.26)$ & $99.30(7.78)$ & 0.004 & $<.001$ & 0.005 \\
\hline GCC avg. $(\mu \mathrm{m})$ & $88.20(6.68)$ & $81.52(8.64)$ & $86.73(4.60)$ & $92.70(4.37)$ & $102.24(6.68)$ & $96.75(4.12)$ & 0.07 & $<.001$ & $<.001$ \\
\hline GCC sup $(\mu \mathrm{m})$ & $88.99(7.31)$ & $82.82(8.16)$ & $87.86(5.11)$ & $91.66(4.96)$ & $100.96(7.20)$ & $96.86(5.37)$ & 0.29 & $<.001$ & $<.001$ \\
\hline $\mathrm{GCC} \inf (\mu \mathrm{m})$ & $87.40(7.04)$ & $80.22(9.91)$ & $85.66(5.02)$ & $93.74(4.05)$ & $103.60(6.56)$ & $96.62(3.73)$ & 0.02 & $<.001$ & $<.001$ \\
\hline FLV \% & $1.68(2.22)$ & $4.50(4.67)$ & $2.41(2.74)$ & $0.20(0.22)$ & $0.34(0.46)$ & $1.00(1.09)$ & 0.001 & $<.001$ & 0.005 \\
\hline GLV \% & $9.59(5.71)$ & $18.07(7.16)$ & $12.29(4.68)$ & $4.69(2.76)$ & $1.57(1.50)$ & $4.99(2.21)$ & 0.006 & $<.001$ & $<.001$ \\
\hline RGC count (n) & $\begin{array}{l}1,002,394.31 \\
(189,401.24)\end{array}$ & $\begin{array}{l}1,183,055.86 \\
(125,256.44)\end{array}$ & $\begin{array}{l}986,664.15 \\
(91,736.86)\end{array}$ & $\begin{array}{l}884,594.19 \\
(128,656.99)\end{array}$ & $\begin{array}{l}1,191,809.55 \\
(129,243.34)\end{array}$ & $\begin{array}{l}1,034,300.79 \\
(109,779.01)\end{array}$ & 0.006 & $<.001$ & 0.005 \\
\hline
\end{tabular}

The parameters are expressed as mean and SD. RNFLavg and RGCs count are significant in all comparisons, while GCCavg is not significant in the comparison between PPG and emmetropes control. $P$-values significant for $p<0.05$ 
Table 6 RNFL and GCC measurement and RGCcount in control eyes subgroups

\begin{tabular}{|c|c|c|c|c|c|c|}
\hline Parameters & $\begin{array}{l}\text { Emmetropic } \\
\text { control }(N=13)\end{array}$ & $\begin{array}{l}\text { Control with } \mathrm{AL} \\
<25 \mathrm{~mm}(\mathrm{~N}=12)\end{array}$ & $\begin{array}{l}\text { Control with } \mathrm{AL} \\
>25 \mathrm{~mm}(\mathrm{~N}=11)\end{array}$ & $\begin{array}{l}\text { Emmetropic Control } \\
\text { vs control with } \mathrm{AL} \\
<25 \mathrm{~mm}\end{array}$ & $\begin{array}{l}\text { Emmetropic Control } \\
\text { vs control with } \mathrm{AL} \\
>25 \mathrm{~mm}\end{array}$ & $\begin{array}{l}\text { Control with } \\
\mathrm{AL}<25 \mathrm{~mm} \text { vs } \\
\text { control with } \\
\mathrm{AL}>25 \mathrm{~mm}\end{array}$ \\
\hline & & & & \multicolumn{3}{|c|}{$P$-values } \\
\hline $\mathrm{MD}(\mathrm{dB})$ & $-0.12(0.85)$ & $-0.64(0.79)$ & $-0.73(0.76)$ & 0.11 & 0.12 & 0.83 \\
\hline RNFL avg. $(\mu \mathrm{m})$ & $109.76(9.79)$ & $114.54(10.61)$ & $100.15(7.59)$ & 0.31 & 0.04 & 0.003 \\
\hline RNFL sup $(\mu \mathrm{m})$ & $106.45(9.32)$ & $113.45(13.76)$ & $101.04(10.04)$ & 0.18 & 0.12 & 0.003 \\
\hline RNFL inf $(\mu m)$ & 113.08 (11.48) & $115.62(9.26)$ & $99.30(7.78)$ & 0.81 & 0.01 & 0.02 \\
\hline GCC avg. $(\mu \mathrm{m})$ & $92.70(4.37)$ & $102.24(6.68)$ & $96.75(4.12)$ & $<.001$ & 0.05 & 0.03 \\
\hline GCC sup $(\mu \mathrm{m})$ & $91.66(4.96)$ & $100.96(7.20)$ & $96.86(5.37)$ & 0.004 & 0.06 & 0.13 \\
\hline GCC inf $(\mu \mathrm{m})$ & $93.74(4.05)$ & $103.60(6.56)$ & $96.62(3.73)$ & $<.001$ & 0.09 & 0.005 \\
\hline FLV \% & $0.20(0.22)$ & $0.34(0.46)$ & $1.00(1.09)$ & 0.60 & 0.04 & 0.05 \\
\hline GLV \% & 4.69 (2.76) & $1.57(1.50)$ & $4.99(2.21)$ & 0.005 & 0.68 & $<.001$ \\
\hline RGC count (n) & $\begin{array}{l}1,183,055.86 \\
(125,256.44)\end{array}$ & $\begin{array}{l}1,191,809.55 \\
(129,243.34)\end{array}$ & $\begin{array}{l}1,034,300.79 \\
(109,779.01)\end{array}$ & 0.76 & 0.01 & 0.007 \\
\hline
\end{tabular}

The parameters are expressed as mean and SD. $P$-values significant for $p<0.05$

thickness, which is more reliable in the evaluation of glaucoma in high myopia.

Also Chen et al. [24] argue that evaluation of glaucoma with nonhighly myopic database could lead to misdiagnosis, and that GCC thickness determined by a myopic database should be used.

In our study RNFL and RGCs count are correlated to the increase in axial length with a moderate significant negative correlation, while GCC thicknesses seem to be the least correlated to axial length increase because they have a weak correlation in all groups, not significant in control group where there is no confounding factor of glaucomatous disease. (Table 3). This is this is in agreement with the results of many studies: Shoji et al. [25] have shown that GCC parameters are not significantly affected by high myopia, while RNFL measurements have a decreased ability to detect glaucoma in myopic subjects. Wang [26] and Scuderi [27] have established that macular GCC thickness has higher diagnostic power than peripapillary RNFL thickness in high myopia.

Considering the results of the comparisons among subgroups (Tables 4, 5, 6 and 7) there are statistically significant results for almost all the parameters in comparison between control group and PPG, both among

Table 7 RNFL and GCC measurement and RCGcount in subgroups with different AL, without distinction of disease stage

\begin{tabular}{|c|c|c|c|c|c|c|c|c|}
\hline & Emmetropic PPG & Myopic $^{a}$ PPG & Myopic Control $^{b}$ & $\begin{array}{l}\text { Non-highly } \\
\text { myopicc }\end{array}$ & Highly myopic ${ }^{d}$ & $\begin{array}{l}\text { Emmetropic } \\
\text { PPG vs } \\
\text { Myopic }{ }^{\text {a PPG }}\end{array}$ & $\begin{array}{l}\text { Myopic }^{b} \\
\text { Control vs } \\
\text { myopic }^{a} \text { PPG }\end{array}$ & $\begin{array}{l}\text { Non-highly } \\
\text { myopic }^{c} \text { vs } \\
\text { highly myopic }^{\mathrm{d}} \\
\end{array}$ \\
\hline & & & & & & \multicolumn{3}{|c|}{$P$-values } \\
\hline $\mathrm{MD}(\mathrm{dB})$ & $-0.98(1.52)$ & $-0.38(1.69)$ & $-0.69(0.76)$ & $-2.12(6.09)$ & $-3.58(5.16)$ & 0.04 & 0.11 & 0.04 \\
\hline RNFL avg. $(\mu \mathrm{m})$ & $97.17(10.82)$ & $91.89(9.07)$ & $107.66(11.68)$ & $94.69(13.23)$ & $86.46(13.87)$ & 0.03 & $<.001$ & 0.002 \\
\hline RNFL sup $(\mu \mathrm{m})$ & $98.01(11.01)$ & 91.91 (10.55) & $107.51(13.44)$ & $95.05(13.26)$ & $88.15(15.30)$ & 0.02 & $<.001$ & 0.06 \\
\hline RNFL inf $(\mu \mathrm{m})$ & $96.31(11.84)$ & 91.86 (11.85) & $107.81(11.82)$ & $94.31(14.57)$ & 84.78 (14.88) & 0.17 & $<.001$ & $<.001$ \\
\hline GCC avg. $(\mu \mathrm{m})$ & $88.20(6.68)$ & $84.12(7.32)$ & $99.61(6.16)$ & $84.77(8.88)$ & 81.61 (11.78) & 0.01 & $<.001$ & 0.03 \\
\hline GCC sup $(\mu \mathrm{m})$ & $88.99(7.31)$ & $85.34(7.19)$ & $99.00(6.59)$ & $86.15(8.62)$ & $83.43(11.79)$ & 0.02 & $<.001$ & 0.04 \\
\hline GCC inf $(\mu \mathrm{m})$ & $87.40(7.04)$ & $82.94(8.24)$ & $100.26(6.37)$ & $83.41(10.58)$ & 79.78 (13.14) & 0.03 & $<.001$ & 0.06 \\
\hline FLV \% & $1.68(2.22)$ & $3.46(3.93)$ & $0.66(0.87)$ & $4.22(3.74)$ & $5.96(5.39)$ & 0.002 & $<.001$ & 0.009 \\
\hline GLV \% & 9.59 (5.71) & $15.18(6.65)$ & $3.21(2.53)$ & $15.19(7.85)$ & 18.39 (10.28) & 0.008 & $<.001$ & 0.06 \\
\hline RGC count (n) & $\begin{array}{l}1,002,394.31 \\
(189,401.24)\end{array}$ & $\begin{array}{l}935,629.17 \\
(121,851.31)\end{array}$ & $\begin{array}{l}1,116,479.27 \\
(142,484.24)\end{array}$ & $\begin{array}{l}910,940.59 \\
(226,819.93)\end{array}$ & $\begin{array}{l}784,036.59 \\
(253,833.31)\end{array}$ & $<.001$ & $<.001$ & $<.001$ \\
\hline
\end{tabular}

The parameters are expressed as mean and SD. $P$-values significant for $p<0.05$

${ }^{a}$ Myopic eyes with preperimetric glaucoma, without distinction for axial length

${ }^{\mathrm{b}}$ Myopic control eyes with no distinction for axial length

cControl and PPG eyes with $\mathrm{AL}<25 \mathrm{~mm}$

${ }^{\mathrm{d}}$ Control and PPG eyes with $\mathrm{AL}>25 \mathrm{~mm}$ 


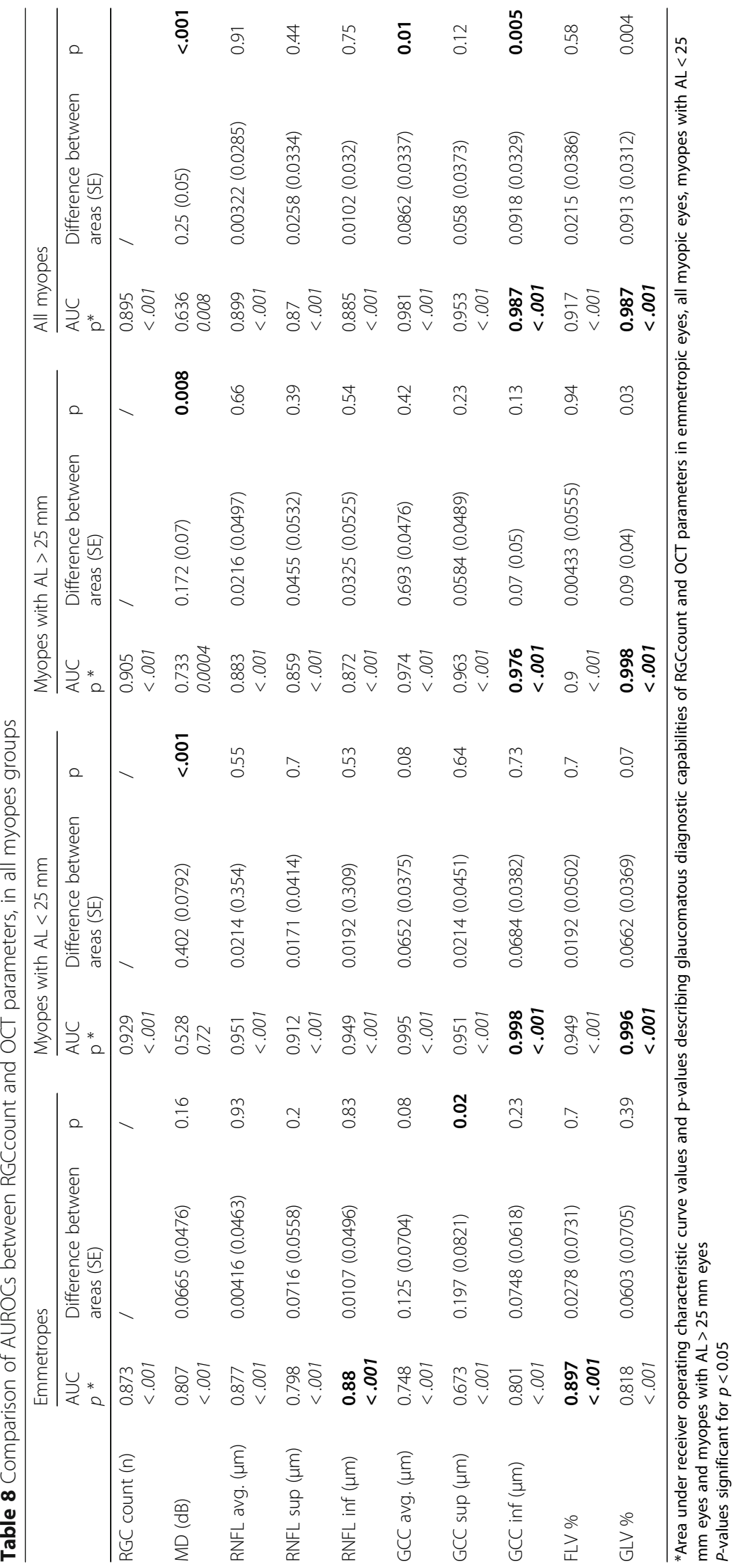



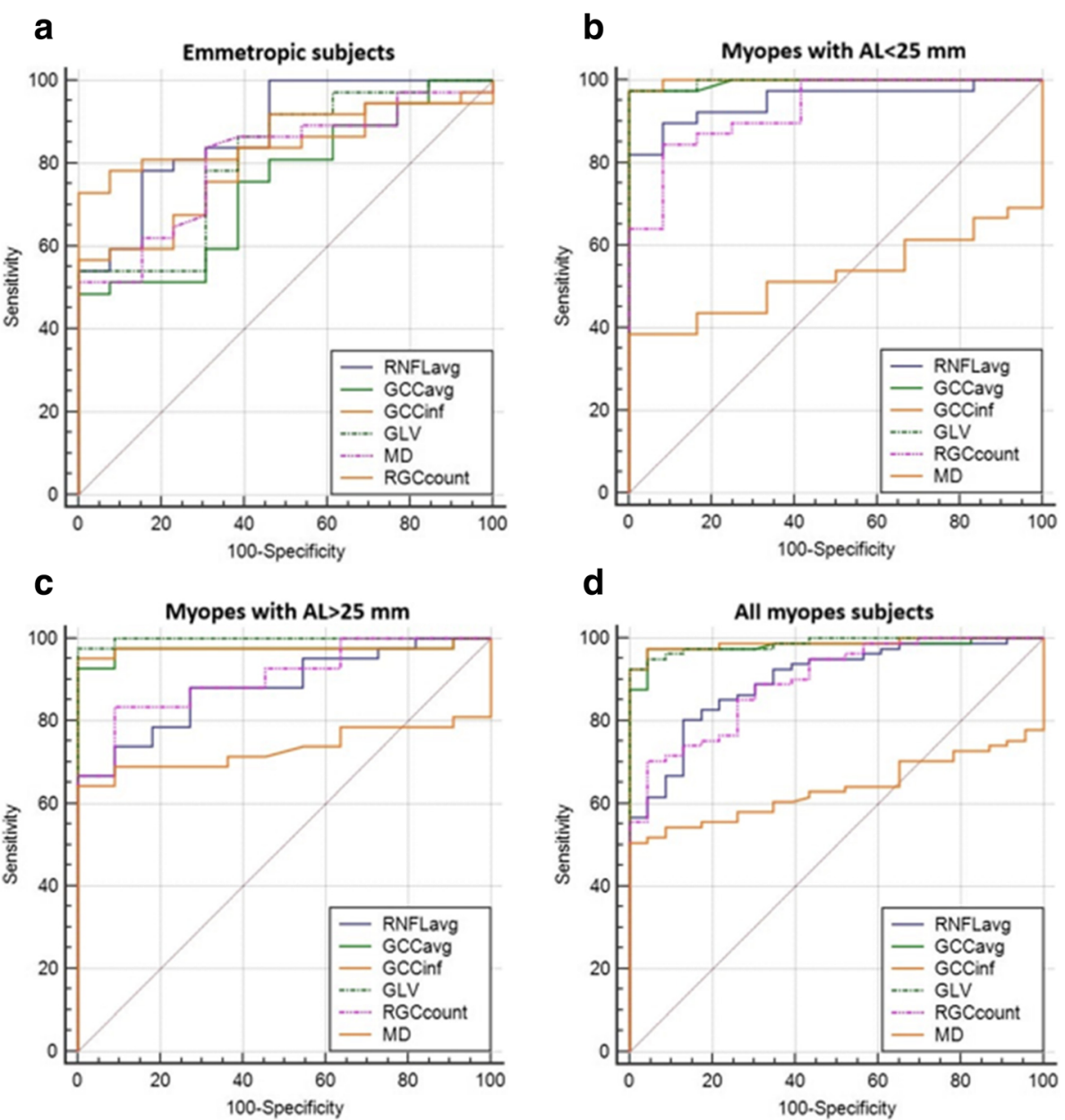

Fig. 2 a-d AUROC of RNFLavg, GCCinf, GLV, RGCcount and MD in emmetropic eyes (a), myopes with $A L<25$ mm (b), myopes with AL $>25 \mathrm{~mm}$ (c) and all myopic eyes with no distinction in axial length (d)

the myopes and emmetropes. So we could support, according to the studies of Tan et al. [28] and Kim et al. [29], that the RNFL and GCC parameters are complementary in the evaluation of glaucomatous damage also in myopic eyes.

As regards diagnostic ability of OCT parameters, in our study all parameters has an AUROC $>0.5$ (Table 8), and all curves are statistical significant, with high values of sensibility and specificity. While RNFLinf and FLV showed the best AUROCs in emmetropes, GCCinf and GLV showed the best AUROCs in all myopic group. This is in agreement with many studies that demonstrated that GCC thickness have a glaucoma detection ability as effective as that of RNFL parameters [25, 28-33].

However we must take into account some limitations of GCC in the evaluation of glaucoma in myopic eyes. In the eyes in which the head of the optic nerve is deformed and therefore difficult to evaluate, we may assume that the macular region is less distorted, but this is not always true. The studies by Kim et al. [34, 35] have suggested that the outline of the entire posterior pole determines the possible configuration of the optic nerve head. So, the presence of irregularities in macular region could invalidate the evaluation of GCC in myopia. Another bias is due to the high axial length which causes a false positive GCC thinning [36]. This is because a greater axial length determines a streching of the globe with an increase in the distance between the optic nerve and the macula and consequent false thinning of macular region [37, 38]. Furthermore, the presence of macular degeneration can cause GCC thinning (for retinal atrophy) or thickening (for intraretinal fluid due to myopic $\mathrm{CNV}$ or to macular retinoschisis) that are independent from glaucoma [39].

To our knowledge, no previous studies have reported on use of RGCs count in identify glaucoma in myopic eyes and its diagnostic ability. There are many studies about RGCcount in non-myopic eyes demonstrating that a combined measure of structural and functional parameters performs better than the single OCT and perimetry 
parameters $[13,16]$. We wanted to evaluate if the diagnostic ability of the RGC was superior to those of the single parameters used in its calculation formula (MD and RNFLavg) also in myopic groups: both in mild and high myopes, AUROCs of RGCcount are significantly better than those of $\mathrm{MD}$, and approximately similar to those of RNFLavg without statistically significant differences (Table 8). In all groups, both myopes and emmetropes, RGCcount shows very good AUROCs (between 0.873 in emmetropes and 0.929 in mild myopes), with sensitivity $>70 \%$ and specificity $>90 \%$.

Based on the results of our study, RGCs count seems to be complementary to OCT parameters in the detection of glaucomatous damage in the myopia, also if GCC parameters show better diagnostic ability. Since the glaucomatous damage in the myopia is more early to be detected at macular level, it could be useful to evaluate the number of macular ganglion cells, as already done by Rolle et al. [15], also in myopic subjects. This could be analysed in a further study.

The limitation of this study is that, despite of a good number of the total sample, the subdivision in different subgroups makes the number of each subgroup reduced. However, this is also found in other studies [40-42]. To validate the results obtained it would be indicated to use an even larger cohort of investigation. In addition, the cross-sectional design of the study is a weak point that limited longitudinal analysis, in fact we are carrying out the creation of a prospective cohort to evaluate the progression of VF in the preperimetric group.

Another limitation is related to the fact that the sample of myopic eyes does not perfectly correspond to what we find in clinical practice, because it does not include all the eyes with perimetric alterations (enlarged blind spot, general reduction of sensitivity and superotemporal peripheral defects), which also are very frequent in myopic eyes.

A strength is represented by the use of preperimetric eyes, since comparing only eyes diagnosed with both functionally and structurally established glaucoma with a control group would lead to overestimate the performance of the test, as reported by Medeiros et al. [43].

\section{Conclusions}

In conclusion, in the OCT analysis of myopic eyes RNFL is the parameter most influenced by the axial length, while the GCC, in particular the inferior, and the GLV are the two OCT parameters with better diagnostic performance. The RGCcount appears to have good sensitivity and specificity, but not higher than the OCT parameters, so it can be used as a complementary test in the diagnosis of glaucoma in myopic eyes.

Identifying the presence of glaucoma in a myopic eye is one of the current diagnostic challenges in ophthalmology, and we must interpret all the instrumental data considering the influence of myopia. Current OCTs analyze the thicknesses of retinal nerve fibers and ganglion cells using a normative database that includes emmetropic subjects. Our study agrees with other works affirming that the OCT parameters are affected, although to varying degrees, by the axial length. Therefore to increase the reliability of the OCT in the diagnosis it would be appropriate to insert myopic eyes in the normative databases of the instruments and develop algorithms that take into account the axial length to analyze the thicknesses detected with OCT.

\section{Abbreviations \\ AL: Axial Length; BCVA: Best Corrected Visual Acuity; FD: Fourier-Domain; FLV: Focal Loss Volume; GCC: Ganglion Cell Complex; GLV: Global Loss Volume; IOP: Intra-Ocular Pressure; MD: Mean Deviation; OCT: Optical Coherence Tomography; ONH: Optic Nerve Head; POAG: Primary Open Angle Glaucoma; PPG: Preperimetric Glaucoma; PSD: Pattern Standard Deviation; RGC: Retinal Ganglion Cell; RNFL: Retinal Nerve Fiber Layer; VF: Visual Field}

\section{Acknowledgements}

Not applicable.

\section{Authors' contributions}

Study concept and design (TR, BB, AM); collection, management, analysis, and interpretation of data (BB, AM); preparation, review, or approval of the manuscript (TR, BB, AM, LD). All authors read and approved the final manuscript.

\section{Funding}

This study was not supported by any research grants.

Availability of data and materials

The data have not been placed in any online data storage. The datasets used and analysed during the current study are available from the corresponding author on reasonable request.

\section{Ethics approval and consent to participate}

This study followed the tenets of the Declaration of Helsinki and approved by the ethics committee of the University \& General Hospital San Giovanni Battista of Torino. Informed written consent was obtained from all participants.

\section{Consent for publication}

Not applicable.

\section{Competing interests}

The authors declare that they have no competing interests.

Received: 3 April 2020 Accepted: 18 August 2020

Published online: 22 September 2020

\section{References}

1. Holden BA, Fricke TR, Wilson DA, et al. Global prevalence of myopia and high myopia and temporal trends from 2000 through 2050. Ophthalmology. 2016;123(5):1036-42.

2. Tham Y-C, Li X, Wong TY, et al. Global prevalence of Glaucoma and projections of Glaucoma burden through 2040. Ophthalmology. 2014 121(11):2081-90.

3. Bourne RRA, Taylor HR, Flaxman SR, et al. Number of People Blind or Visually Impaired by Glaucoma Worldwide and in World Regions 19902010: A Meta-Analysis. PLoS One. 2016;11(10):e0162229.

4. Rudnicka AR, Mt-Isa S, Owen CG, et al. Variations in primary open-angle Glaucoma prevalence by age, gender, and race: a Bayesian meta-analysis. Invest Ophthalmol Vis Sci. 2006;47(10):4254-61. 
5. Marcus MW, de Vries MM, Montolio FGJ, et al. Myopia as a Risk Factor for Open-Angle Glaucoma: A Systematic Review and Meta-Analysis. Ophthalmology. 2011;118(10):1989-1994.e2.

6. Tan NYQ, Sng CCA, Jonas JB, et al. Glaucoma in myopia: diagnostic dilemmas. Br J Ophthalmol. 2019;103(10):1347-55.

7. Leung CK-S, Yu M, Weinreb RN, et al. Retinal nerve Fiber layer imaging with spectral-domain optical coherence tomography: interpreting the RNFL maps in healthy myopic eyes. Invest Ophthalmol Vis Sci. 2012;53(11):7194-200.

8. Harwerth RS, Wheat JL, Fredette MJ, et al. Linking structure and function in Glaucoma. Prog Retin Eye Res. 2010;29(4):249-71.

9. Medeiros FA, Lisboa R, Weinreb RN, et al. A combined index of structure and function for staging glaucomatous damage. Arch Ophthalmol. 2012 130(9):1107-16.

10. Medeiros FA, Zangwill LM, Bowd C, et al. The structure and function relationship in glaucoma: implications for detection of progression and measurement of rates of change. Invest Ophthalmol Vis Sci. 2012:53(11): 6939-46.

11. Medeiros FA, Zangwill LM, Anderson DR, et al. Estimating the rate of retinal ganglion cell loss in glaucoma. Am J Ophthalmol. 2012;154(5):814-824.e1.

12. Marvasti AH, Tatham AJ, Zangwill LM, et al. The Relationship between Visual Field Index and Estimated Number of Retinal Ganglion Cells in Glaucoma. PLoS One. 2013;8(10):e76590.

13. Medeiros FA, Lisboa $R$, Weinreb RN, et al. Retinal ganglion cell count estimates associated with early development of visual field defects in Glaucoma. Ophthalmology. 2013;120(4):736-44.

14. Hodapp E, Parrish RK II, Anderson D. Clinical Decisions in Glaucoma. St. Louis: Mosby-Year Book Medical Publishers; 1993.

15. Rolle T, Dallorto L, Bonetti B. Retinal and macular ganglion cell count estimated with optical coherence tomography RTVUE-100 as a candidate biomarker for Glaucoma. Invest Ophthalmol Vis Sci. 2016;57(13):5772-9.

16. Zhang C, Tatham AJ, Weinreb RN, et al. Relationship between ganglion cell layer thickness and estimated retinal ganglion cell counts in the glaucomatous macula. Ophthalmology. 2014;121(12):2371-9.

17. DeLong ER, DeLong DM, Clarke-Pearson DL. Comparing the areas under two or more correlated receiver operating characteristic curves: a nonparametric approach. Biometrics. 1988:44(3):837-45.

18. Esporcatte BLB, Kara-José AC, Melo LAS, et al. The estimates of retinal ganglion cell counts performed better than isolated structure and functional tests for Glaucoma diagnosis. J Ophthalmol. 2017;2017:2724312.

19. Budenz DL, Anderson DR, Varma R, et al. Determinants of Normal retinal nerve Fiber layer thickness measured by stratus OCT. Ophthalmology. 2007; 114(6):1046-52.

20. Pan C-W, Cheung CY, Aung T, et al. Differential associations of myopia with major age-related eye diseases. Ophthalmology. 2013;120(2):284-91.

21. Nakanishi H, Akagi T, Hangai M, et al. Sensitivity and specificity for detecting early glaucoma in eyes with high myopia from normative database of macular ganglion cell complex thickness obtained from normal non-myopic or highly myopic Asian eyes. Graefes Arch Clin Exp Ophthalmol. 2015;253(7):1143-52.

22. Medeiros FA, Zangwill LM, Bowd C, et al. Evaluation of retinal nerve fiber layer, optic nerve head, and macular thickness measurements for glaucoma detection using optical coherence tomography. Am J Ophthalmol. 2005;139(1):44-55.

23. Shin H-Y, Park H-YL, Park CK. The effect of myopic optic disc tilt on measurement of spectral-domain optical coherence tomography parameters. Br J Ophthalmol. 2015;99(1):69-74.

24. Chen HS-L, Liu C-H, Lu D-W. Comparison of glaucoma diagnostic accuracy of macular ganglion cell complex thickness based on nonhighly myopic and highly myopic normative database. Taiwan J Ophthalmol. 2016;6(1):15-20.

25. Shoji T, Sato H, Ishida M, et al. Assessment of glaucomatous changes in subjects with high myopia using spectral domain optical coherence tomography. Invest Ophthalmol Vis Sci. 2011;52(2):1098-102.

26. Wang W-W, Wang H-Z, Liu J-R, et al. Diagnostic ability of ganglion cell complex thickness to detect glaucoma in high myopia eyes by Fourie domain optical coherence tomography. Int J Ophthalmol. 2018;11(5):791-6.

27. Scuderi G, Fragiotta S, Scuderi L, et al. Ganglion cell complex analysis in Glaucoma patients: what can it tell us? Eye Brain. 2020;12:33-44.

28. Tan O, Chopra V, Lu AT-H, et al. Detection of macular ganglion cell loss in glaucoma by Fourier-domain optical coherence tomography. Ophthalmology. 2009;116(12):2305-2314.e1-2.

29. Kim NR, Lee ES, Seong GJ, et al. Comparing the ganglion cell complex and retinal nerve fibre layer measurements by Fourier domain OCT to detect glaucoma in high myopia. Br J Ophthalmol. 2011;95(8):1115-21.
30. Rao HL, Babu JG, Addepalli UK, et al. Retinal nerve fiber layer and macular inner retina measurements by spectral domain optical coherence tomograph in Indian eyes with early glaucoma. Eye Lond Engl. 2012;26(1):133-9.

31. Seong M, Sung KR, Choi EH, et al. Macular and Peripapillary retinal nerve Fiber layer measurements by spectral domain optical coherence tomography in Normal-tension Glaucoma. Invest Ophthalmol Vis Sci. 2010;51(3):1446-52.

32. Garas A, Vargha P, Holló G. Diagnostic accuracy of nerve fibre layer, macular thickness and optic disc measurements made with the RTVue-100 optical coherence tomograph to detect glaucoma. Eye Lond Engl. 2011;25(1):57-65.

33. Schulze A, Lamparter J, Pfeiffer $\mathrm{N}$, et al. Diagnostic ability of retinal ganglion cell complex, retinal nerve fiber layer, and optic nerve head measurements by Fourier-domain optical coherence tomography. Graefes Arch Clin Exp Ophthalmol. 2011;249(7):1039-45.

34. Seol BR, Jeoung JW, Park KH. Glaucoma detection ability of macular ganglion cell-inner Plexiform layer thickness in myopic Preperimetric Glaucoma. Invest Ophthalmol Vis Sci. 2015;56(13):8306-13.

35. Kim YC, Moon J-S, Park H-YL, et al. Three dimensional evaluation of posterior pole and optic nerve head in tilted disc. Sci Rep. 2018;8(1):1121.

36. Kim YC, Jung Y, Park HL, et al. The location of the deepest point of the eyeball determines the optic disc configuration. Sci Rep. 2017;7(1):5881.

37. Kim KE, Jeoung JW, Park KH, et al. Diagnostic classification of macular ganglion cell and retinal nerve fiber layer analysis: differentiation of falsepositives from glaucoma. Ophthalmology. 2015;122(3):502-10.

38. Song WK, Lee SC, Lee ES, et al. Macular thickness variations with sex, age, and axial length in healthy subjects: a spectral domain-optical coherence tomography study. Invest Ophthalmol Vis Sci. 2010;51(8):3913-8.

39. Qiu K, Wang G, Zhang R, et al. Influence of optic disc-fovea distance on macular thickness measurements with OCT in healthy myopic eyes. Sci Rep. 2018:8(1):5233

40. Benhamou $N$, Massin $P$, Haouchine $B$, et al. Macular retinoschisis in highly myopic eyes. Am J Ophthalmol. 2002;133(6):794-800.

41. Xu X-Y, Xiao H, Luo J-Y, et al. Evaluation of spectral domain optical coherence tomography parameters in discriminating preperimetric glaucoma from high myopia. Int J Ophthalmol. 2019;12(1):58-65.

42. Leung CK-S, Mohamed S, Leung KS, et al. Retinal nerve Fiber laye measurements in myopia: an optical coherence tomography study. Invest Ophthalmol Vis Sci. 2006:47(12):5171-6.

43. Medeiros FA, Ng D, Zangwill LM, et al. The effects of study design and Spectrum Bias on the evaluation of diagnostic accuracy of confocal scanning laser ophthalmoscopy in Glaucoma. Invest Ophthalmol Vis Sci. 2007:48(1):214-22.

\section{Publisher's Note}

Springer Nature remains neutral with regard to jurisdictional claims in published maps and institutional affiliations.

Ready to submit your research? Choose BMC and benefit from:

- fast, convenient online submission

- thorough peer review by experienced researchers in your field

- rapid publication on acceptance

- support for research data, including large and complex data types

- gold Open Access which fosters wider collaboration and increased citations

- maximum visibility for your research: over $100 \mathrm{M}$ website views per year

At $\mathrm{BMC}$, research is always in progress.

Learn more biomedcentral.com/submissions 